\title{
Effect of Inhaled Nitric Oxide on Cerebrospinal Fluid and Blood Nitrite Concentrations in Newborn Lambs
}

\author{
GEORGE R. CONAHEY, GORDON G. POWER, ANDREW O. HOPPER, MICHAEL H. TERRY, LAURA S. KIRBY, \\ AND ARLIN B. BLOOD \\ Center for Perinatal Biology [G.G.P., A.B.B.], Departments of Pediatrics [G.R.C., A.O.H., L.S.K., A.B.B.], Respiratory Care [M.H.T.], \\ Loma Linda University, Loma Linda, California 92354
}

\begin{abstract}
Inhaled nitric oxide (iNO) has many extrapulmonary effects. As the half-life of nitric oxide (NO) in blood is orders of magnitude less than the circulation time from lungs to the brain, the mediator of systemic effects of iNO is unknown. We hypothesized that concentrations of nitrite, a circulating byproduct of NO with demonstrated NO bioactivity, would increase in blood and cerebrospinal fluid (CSF) during iNO therapy. iNO (80 ppm) was given to six newborn lambs and results compared with six control lambs. Blood and CSF nitrite concentrations increased 2-fold in response to iNO. cGMP increased in blood but not CSF suggesting brain guanylate cyclase activity was not increased. When sodium nitrite was infused i.v. blood and CSF nitrite levels increased within 10 min and reached similar levels of $14.6 \pm 1.5 \mu \mathrm{M}$ after $40 \mathrm{~min}$. The reactivity of nitrite in Hb-free brain homogenates was investigated, with the findings that nitrite did not disappear nor did measurable amounts of s-nitroso, n-nitroso, or iron-nitrosyl-species appear. We conclude that although nitrite diffuses freely between blood and CSF, due to its lack of reactivity in the brain, nitrite's putative role as the mediator of the systemic effects of iNO is limited to intravascular reactions. (Pediatr
\end{abstract} Res 64: 375-380, 2008)

$\mathrm{I}_{\mathrm{t} \rightarrow 3}^{\mathrm{n}}$ nhaled nitric oxide (iNO) is now a well-established therapy for the treatment of pulmonary hypertension in term infants (1-3). Although the vasodilatory effects of iNO are largely selective to the pulmonary vasculature, peripheral actions are also observed throughout the body (4-6). iNO therapy has been shown to reduce the incidence of severe intracerebral hemorrhage and periventricular leukomalacia in select groups of premature infants $(7,8)$ and cerebral palsy $(9)$ and improves neurodevelopmental outcome at 18 mo of age (10). These studies indicate that nitric oxide (NO) bioactivity can be taken up by blood flowing through the lungs and carried systemically. However, $\mathrm{NO}$ reacts rapidly with $\mathrm{Hb}$ and its half-life in blood is only milliseconds (11). Therefore, attention has been directed toward more stable circulating metabolites of NO that might confer the systemic bioactivity of iNO.

The nitrite anion, $\mathrm{NO}_{2}{ }^{-}$, meets many of the criteria for being a mediator of the systemic effects of iNO. Nitrite, produced in the plasma from the oxidation of NO (12), is

Received February 15, 2008; accepted May 6, 2008.

Correspondence: Arlin B. Blood, Ph.D., Department of Pediatrics, Division of Neonatology, School of Medicine, Loma Linda University, Loma Linda, CA 92354; e-mail: ablood@1lu.edu

Supported in part by grant R01-HL65494 from the National Institutes of Health (G.G.P.).

Supplementary material available online at www.pedresearch.com. present in the blood of mammals at mid-nanomolar concentrations (13). Although it was thought until recently to be biologically inert at these concentrations, there is now evidence that under hypoxic/ischemic conditions nitrite becomes a significant source of $\mathrm{NO}$ by a number of biochemical pathways. Evidence that nitrite is a potent cytoprotective source of $\mathrm{NO}$ during hypoxic/ischemic stress is provided by animal studies in the liver, heart, brain and kidney (Lundberg et al. (14)).

Based on evidence of systemic effects of iNO and bioactivity of nitrite, we hypothesized that the neuroprotective effects of iNO are mediated by its conversion to nitrite in the pulmonary capillaries followed by transport of nitrite into the brain where it would be converted back into NO. To investigate this possibility, experiments were carried out to detect changes in the concentrations of nitrite and cGMP in the blood and cerebrospinal fluid (CSF) of newborn lambs in response to treatment with iNO. In addition, the kinetics of nitrite movement between the blood and CSF, and metabolic clearance rate of $\mathrm{NO}_{2}{ }^{-}$from blood in vivo were determined. Finally, the bioactivity of $\mathrm{NO}_{2}{ }^{-}$in $\mathrm{Hb}$-free brain homogenates was assessed.

\section{METHODS}

Newborn lambs at $10-20 \mathrm{~d}$ of age were used for these studies. Protocols were approved by the Loma Linda University Institutional Animal Care and Use Committee. Additional details regarding the methods used herein may be found in Supplemental Materials (available online at www.pedresearch.org).

The lambs were anesthetized with $10 \mathrm{mg} / \mathrm{kg}$ of short-acting i.v. barbiturate, an endotracheal tube inserted, and anesthesia then continued with $1.5 \%$ halothane in $\mathrm{O}_{2}$ from a volume respirator. Lambs were instrumented with bilateral brachial arterial and femoral venous catheters and a rectal thermistor for monitoring arterial blood pressure and heart rate, drug infusions, blood sampling, and temperature measure. A catheter was placed in the fourth ventricle by passage from the suboccipital regions for CSF sampling. The concentration of $\mathrm{O}_{2}$ used during the instrumentation period was 1.0. Inhalation anesthesia was then discontinued and anesthesia was maintained thereafter by morphine given i.v. (bolus $0.5 \mathrm{mg} \mathrm{kg}^{-1}$ and continuing infusion of $\left.0.1 \mathrm{mg} \mathrm{kg}^{-1} \mathrm{~h}^{-1}\right)$ in association with vecuronium $\left(0.1 \mathrm{mg} \mathrm{kg}^{-1} \cdot \mathrm{h}^{-1}\right)$. This regime was used to mimic clinical maintenance of newborn humans receiving $\mathrm{NO}$ therapy. Upon discontinuation of inhalation anesthesia, $\mathrm{FiO}_{2}$ was also decreased to 0.30 for the remainder of the experiment.

Inhaled NO. A total of twelve lambs were randomly assigned to either a control $(n=6)$ or iNO $(n=6)$ group. To exclude endogenous NO production, $\mathrm{N}$-nitro-L-arginine-methyl-ester (L-NAME) was administered $\left(60 \mathrm{mg} \cdot \mathrm{kg}^{-1}\right.$ bolus i.v. followed by $2 \mathrm{mg} \cdot \mathrm{kg}^{-1} \cdot \mathrm{h}^{-1}$ continuous infusion) beginning 15 min before of the start of iNO treatment. After a baseline period, iNO ( 80 $\mathrm{ppm}$ ) was administered for $30 \mathrm{~min}$ (INOvent, iNO Therapeutics, Clinton, NJ) followed by a 1-h recovery period. As discussed later, this dose of iNO was

Abbreviations: iNO, inhaled nitric oxide; CSF, cerebrospinal fluid; HbNO, iron nitrosyl hemoglobin 
chosen to ensure detectable increases in blood nitrite concentrations against which CSF could be compared. Blood and CSF samples were collected simultaneously at baseline (before initiation of L-NAME), 1 min before initiation of iNO, and 15, 30, 60, and $90 \mathrm{~min}$ after initiation of iNO. A control group of lambs was also studied in which L-NAME was administered but iNO was withheld.

Sodium nitrite infusion. In nine of the twelve lambs studied above (six from the control group and three from the iNO group), and on completion of the recovery period of the iNO protocol, sodium nitrite was infused i.v. for $120 \mathrm{~min}\left(0.6-2.5 \mathrm{mg} \cdot \mathrm{kg}^{-1}\right.$ bolus followed by $1 \mathrm{mg} \cdot \mathrm{kg}^{-1} \cdot \mathrm{h}^{-1}$ infusion). Blood and CSF samples were collected simultaneously at baseline, 10, 20, 40, $60,80,100$, and 120 min during the infusion and $30 \mathrm{~min}$ after termination of the infusion.

Blood and CSF sample processing. Two-milliliter arterial blood samples were collected in heparinized syringes for determination of blood gases, $\mathrm{pH}$, $\mathrm{Hb}$, oxyhemoglobin, and methemoglobin concentrations (ABL5 and OSM3 hemoximeter, Radiometer, Copenhagen). An aliquot of the sample was added to a nitrite stabilization solution for measurement of nitrite by triiodide chemiluminescence method (15). CSF and plasma cGMP concentrations were determined via competitive enzyme immunosorbent assay (EIA; Cayman Chemical, Ann Arbor, MI).

Calculation of a blood-CSF transfer coefficient. A transfer coefficient $\left(t_{\mathrm{c}}\right)$ for the movement of nitrite between the blood and CSF was determined by fitting experimental data to a two-compartment model of blood-to-CSF transfer during constant infusion of nitrite. Details of this model, written in BASIC, are found in the Supplemental Materials (available online at www. pedresearch.org).

Nitrite metabolism in brain homogenates. To investigate nitrite metabolism in brain tissue, homogenates of adult ovine brain were studied in vitro. After both carotids had been perfused with 1 liter of cold saline to remove blood from the cerebral circulation brain samples were excised, mixed with 2 volumes of Tris-buffered saline, and homogenized (Polytron, Brinkman Instr, Westury, NY). Oxygen tensions were reduced to 10-20 Torr tonometrically by equilibration with $3 \% \mathrm{CO}_{2}$ in a balance of $\mathrm{N}_{2}$, and homogenates were transferred anaerobically to sealed vials and warmed to $39^{\circ} \mathrm{C}$.

Sodium nitrite was injected to achieve an initial concentration of $100 \mu \mathrm{M}$. Samples were collected over time for measurement of nitroso species including s-nitrosothiols, nitrosylated iron, and n-nitrosamines as previously described (16), as well as nitrite. Total nitrite and nitroso-species concentrations were determined by injection of the first aliquot into the triiodide solution in line with a chemiluminescence NO analyzer. The second aliquot was treated with acid sulfanilamide to remove free nitrite before chemiluminescence detection. The third aliquot was treated with both sulfanilamide and $\mathrm{HgCl}_{2}$ to remove both nitrite and s-nitrosothiols for measurement of iron-nitrosyl and n-nitrosamine species.

Statistical analysis. One-way analysis of variance was used to detect significant changes from baseline measurements over time. Two-way analysis of variance with repeated measures was used to detect differences between control and iNO groups. Bonferroni's post hoc test was used to detect differences at specific data points. Means are presented with their standard errors. The software GraphPad Prism v5.0 for Macintosh (GraphPad Software, Inc, San Diego, CA) was used for statistical analyses.

\section{RESULTS}

The weight of the twelve lambs studied averaged $5.5 \pm 0.5$ $\mathrm{kg}$, with no significant baseline differences between the iNO and control groups. Baseline blood gases, methemoglobin levels and arterial blood pressures are provided in Figure 1 and were in the normal range.

Effects of iNO. Administration of iNO resulted in significant increases in blood nitrite after 15 and 30 min of inhalation, with a return to baseline values within $30 \mathrm{~min}$ after the end of iNO treatment (Fig. 2). Nitrite concentrations in the CSF increased more slowly and did not become significantly elevated above baseline levels until $30 \mathrm{~min}$ after the end of the iNO treatment period, and then returned to baseline levels 30 min later. Plasma cGMP concentrations increased significantly above baseline during iNO treatment and also above levels in control animals (Fig. 3). cGMP concentrations in the

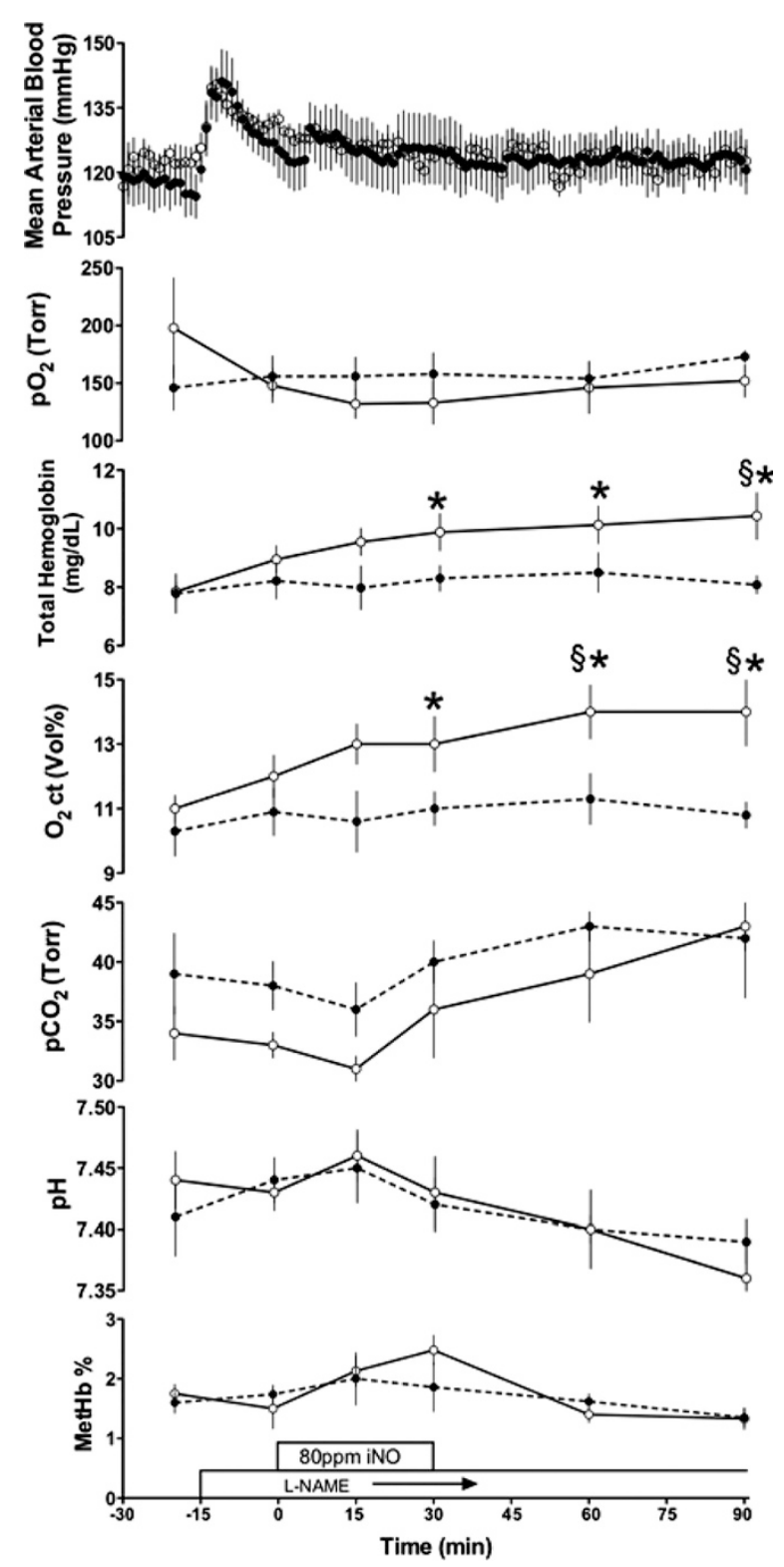

Figure 1. Time course of changes in mean arterial blood pressure and arterial $\mathrm{Po}_{2}$, oxygen content $\left(\mathrm{O}_{2} \mathrm{ct}\right), \mathrm{PCO}_{2}, \mathrm{pH}$, and methemoglobin (MetHb) concentrations. Both control $(\bullet)$ and iNO $(\bigcirc)$ animals received L-NAME infusion. *Indicates significant difference from baseline values ( $p \leq 0.01)$; §indicates significant difference between control and experimental values $(p \leq 0.01)$.

CSF were measurably higher than plasma levels at all time points and remained stable throughout the experiments.

Methemoglobin concentration increased from baseline levels of $1.7 \pm 0.2 \%$ to reach a peak of $2.5 \pm 0.2$ after $30 \mathrm{~min}$ of iNO, a change that did not reach significance.

Results of i.v. infusion of nitrite. Sodium nitrite was infused to measure the $t_{\mathrm{c}}$ of nitrite between blood and CSF. Physiologic responses to the nitrite infusion are shown in Figure 4, and blood and CSF nitrite concentrations are shown in Figure 5. After about $45 \mathrm{~min}$, blood and CSF nitrite concentrations were stable and no longer measurably different from one another. The average blood level thereafter was used to calculate the clearance rate for each lamb. Blood nitrite concentrations averaged $14.6 \pm 1.5 \mu \mathrm{M}$ and the metabolic clearance rate was then readily calculated as the rate of nitrite 

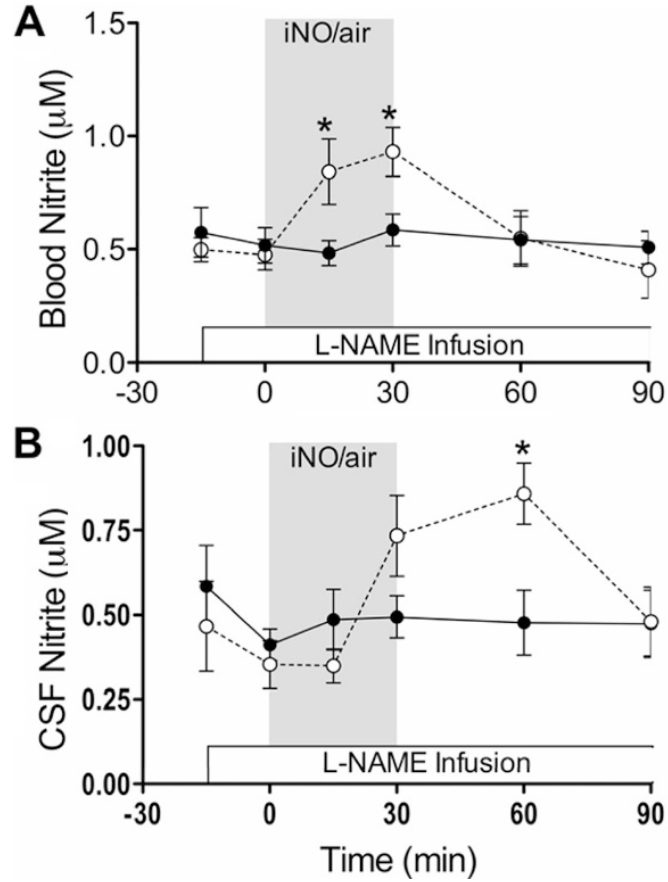

Figure 2. Time profile of whole blood $(A)$ and CSF nitrite $(B)$ concentrations in response to L-NAME and addition of $80 \mathrm{ppm} \mathrm{NO}$ to inspired air $(\bigcirc)$ compared with controls $(\bullet)$. $*$ Indicates significant difference from baseline reached after L-NAME infusion $(p \leq 0.01)$

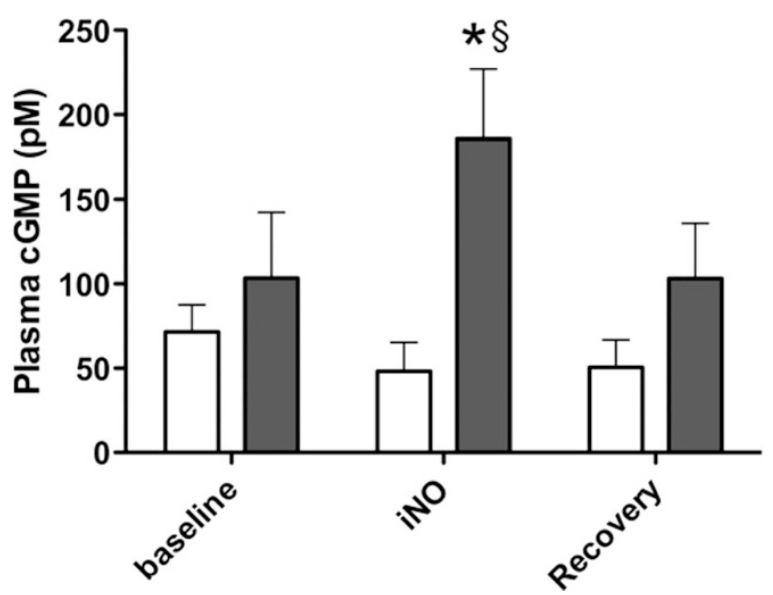

Figure 3. Plasma cGMP concentrations before, during, and after $80 \mathrm{ppm}$ iNO ( $\square$ ) compared with controls $(\square)$. Baseline samples were collected after initiation of L-NAME infusion but before initiation of iNO. *Indicates significant difference from baseline values $(p \leq 0.01)$; §indicates significant difference from control values $(p \leq 0.01)$.

infusion $\left(0.24 \mu \mathrm{mol} \cdot \mathrm{min}^{-1} \cdot \mathrm{kg}^{-1}\right)$ divided by this blood level. The result averaged $16.4 \pm 1.7 \mathrm{~mL} \cdot \mathrm{min}^{-1} \cdot \mathrm{kg}^{-1}$ for these lambs weighing $5.5 \mathrm{~kg}$. After stopping the infusion, whole blood nitrite concentrations decreased with an apparent half time of $28.3 \pm 3.6 \mathrm{~min}$, somewhat longer than found earlier after bolus injections (17), suggesting nitrite had entered slower equilibrating compartments during the prolonged infusion. In the CSF, nitrite levels fell with an apparent half-life of $61 \pm 9$ min.

The highly diffusible compound urea was used as a time marker for passage from the fourth ventricle to sampling site.
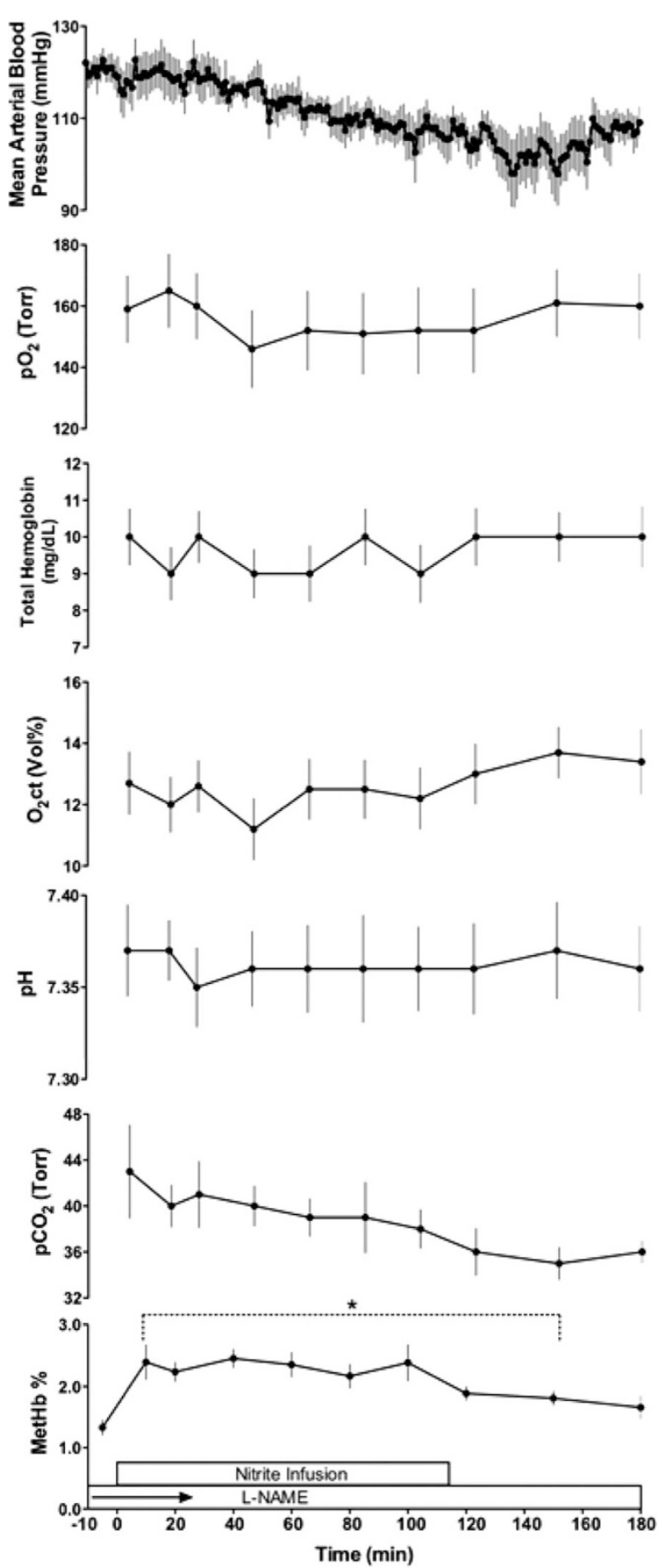

Figure 4. Time course of changes in mean arterial blood pressure, $\mathrm{Po}_{2}$, oxygen content $\left(\mathrm{O}_{2} \mathrm{ct}\right), \mathrm{PCO}_{2}, \mathrm{pH}$, and methemoglobin (MetHb) levels before and during a 120 -min i.v. infusion of nitrite. *Indicates significant difference from baseline values $(p \leq 0.01)$.

After an i.v. bolus $\left(0.2 \mathrm{~g} \cdot \mathrm{kg}^{-1}\right)$, its concentration had peaked in less than $5 \mathrm{~min}$ and thereafter declined $(n=3$, data not shown). Because this time interval is appreciably less than the $15 \mathrm{~min}$ that elapsed before the first collections were made for nitrite infusion, it was felt justified not to correct for delays occasioned by transit of nitrite from the CSF-formation site to the sampling catheter.

Nitrite infusion resulted in significant increases in both plasma and CSF cGMP concentrations. Levels remained elevated for $30 \mathrm{~min}$ after the end of nitrite infusion, as shown in 


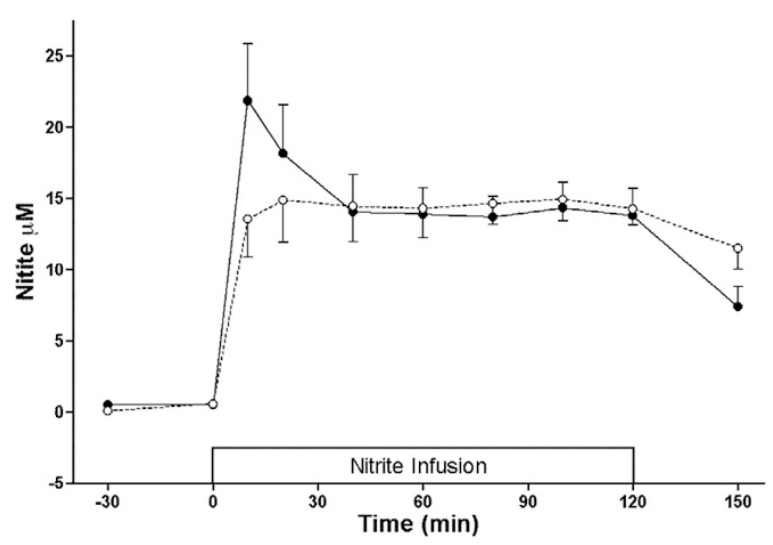

Figure 5. Blood $(-)$ and $\operatorname{CSF}(\bigcirc)$ nitrite responses to an initial bolus and then continuing infusion of nitrite, showing apparent steady state after $\sim 40 \mathrm{~min}$. Average values thereafter were used to calculate the metabolic clearance rate of nitrite.
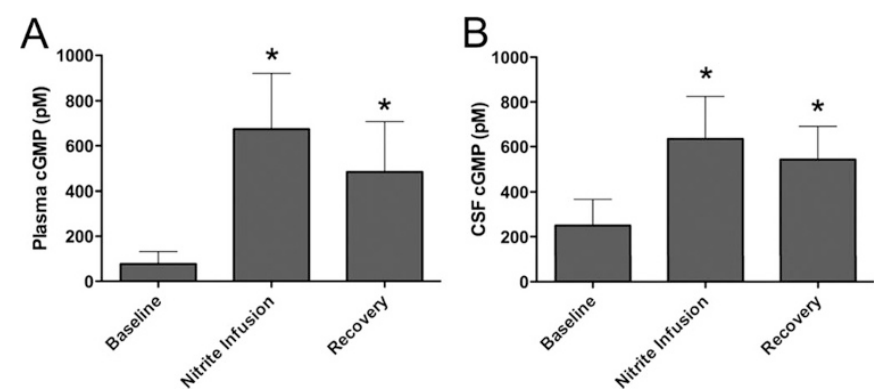

Figure 6. Blood $(A)$ and CSF $(B)$ cGMP concentrations before, during, and after continuous i.v. infusion of nitrite. *Indicates significant difference from baseline reached after L-NAME infusion $(p \leq 0.01)$.

Figure 6. The blood-to-CSF transfer coefficient, $t_{\mathrm{c}}$, averaged $3.7 \pm 0.6 \times 10^{-4}$ micromoles of nitrite flux per min per unit micromolar blood-to-CSF difference.

Nitrite metabolism in homogenates of ovine brain tissue. After addition of sodium nitrite to an initial concentration of $100 \mu \mathrm{M}$ no significant changes in nitrite concentrations were observed during a 60-min period of observation. Nor was there significant production of nitroso species during this time. The average results for three adult sheep are shown in Figure $7 A$. A demonstration of the specificity of the analytical method for SNO is shown in Figure $7 B$.

\section{DISCUSSION}

The present experiments provide evidence that nitrite levels increase in blood and CSF because of iNO treatment in newborn lambs. Circulating concentrations of cGMP, a downstream product of NO-mediated activation of guanylate cyclase, also increase 2-fold as a result of iNO. The experimental findings also demonstrate for the first time that circulating nitrite, provided either by i.v. infusion or indirectly by inhalation of NO, freely, rapidly and reversibly enters the CSF and reaches levels comparable to those in the blood. These observations of the movement of nitrite between the blood and brain are consistent with a neuroprotective role for iNO acting via nitrite. However, the experiments provide no evidence of NO production from nitrite within the brain, suggesting any

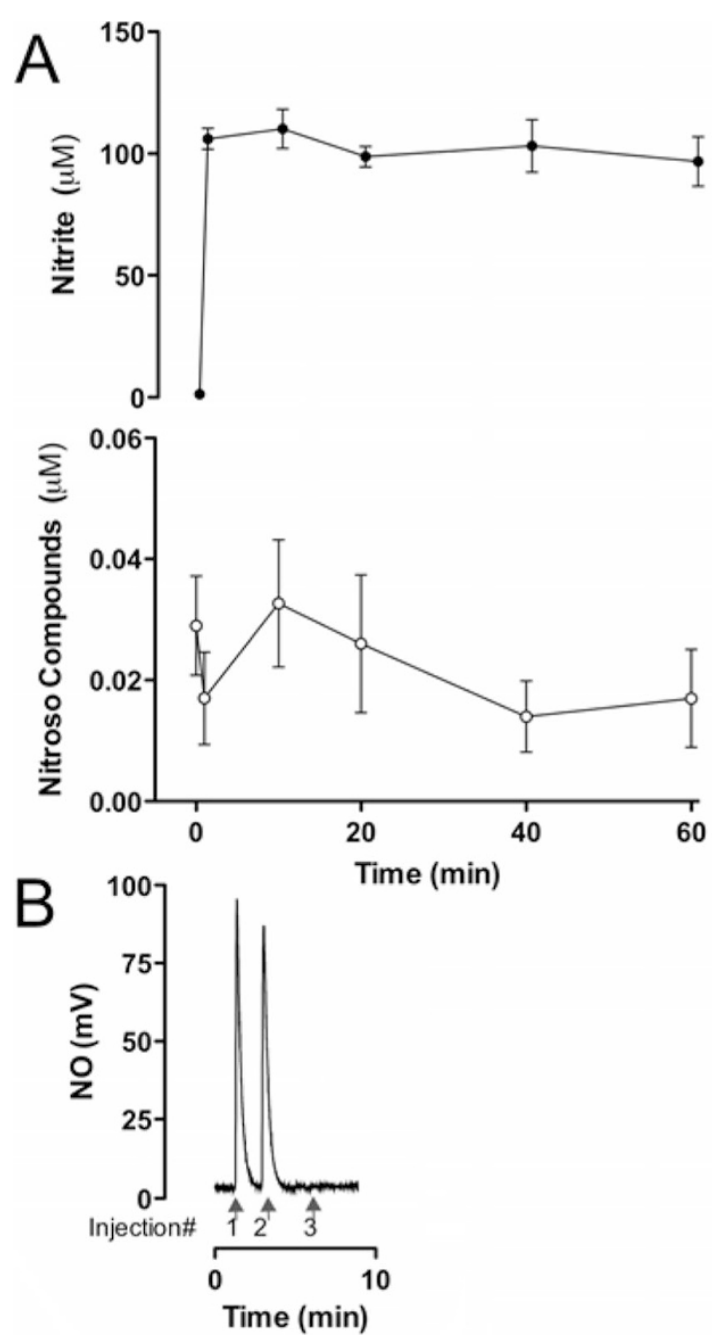

Figure 7. (A) Time course of changes in nitrite and nitroso-species concentrations in brain homogenate after addition of $100 \mu \mathrm{M}$ nitrite $(n=3)$. (B) Demonstration of the selectivity of the assay for nitrosothiols. Nitrosated cysteine standard was injected into the triiodide purge vessel either untreated (Injection 1), after treatment with acidified sulfanilamide to remove free nitrite (Injection 2), or after treatment with $\mathrm{HgCl}_{2}$ and acidified sulfanilamide to convert s-nitrosothiols to nitrite which is then removed from detection by the sulfanilamide (Injection 3).

neuroprotective role for nitrite may be limited to vascular regulation.

Previous studies have shown that the effects of iNO therapy are not limited to the lungs. Administration of iNO has been shown to increase renal blood flow and GFR during iNO (40 $\mathrm{ppm}$ ) in pigs (4), decrease platelet aggregation and increase aortic cGMP content in the rat (6), increase mesentery flow in cats (18), decrease peripheral resistance in sheep (19), and increase forearm blood flow in humans (5). A number of clinical studies have also investigated the possible neuroprotective effects of iNO in the premature newborn with conflicting results. iNO is associated with decreased incidence of severe intraventricular hemorrhage and periventricular leukomalacia in subgroups of preterm infants (7), improved neurodevelopmental outcome at 18 mo of age (10), decreased incidence of intracranial hemorrhage and ventriculomegaly (8), and decreased incidence of cerebral palsy (9). In contrast, the use of iNO in extremely premature infants $(<1000 \mathrm{~g})$ has 
also been shown to increase the incidence of intraventricular hemorrhage (20) with no effect on neurodevelopmental outcome (21). Thus, further controlled clinical trials are needed to investigate the potential neurologic benefit of iNO administration to the premature infant. Nonetheless, much evidence indicates NO bioactivity can be transported throughout the body. However, $\mathrm{Hb}$ rapidly scavenges free NO so that the half-life of NO in whole blood is about $10 \mathrm{~ms}$ (22). Therefore, iNO entering the pulmonary blood is likely metabolized before leaving the lung, suggesting iNO's systemic effects are mediated by metabolites of NO.

In recent years, nitrite has been proposed as a circulating reservoir of NO bioactivity. It is normally present at mid nanomolar concentrations in plasma (13), and is formed there as an oxidation product of endogenously released NO (12). Nitrite can be reduced back to NO by a number of different biochemical pathways, most of which are favored in acidic and hypoxic tissues (Lundberg et al. (14)).

In this study, we hypothesized that iNO would be converted to nitrite in the lung, carried to the brain via the blood, and enter the CSF and brain tissue. This hypothesis is supported by our observations of the effects of iNO on blood and CSF nitrite concentrations. We found that iNO does result in increased concentrations of nitrite in the blood. Furthermore, the current experiments demonstrate for the first time that iNO can result in increased nitrite concentrations within the brain itself. That nitrite moves freely between the blood and CSF is further supported by the current measurements of increased CSF nitrite concentrations during i.v. nitrite infusion.

There is a growing consensus that nitrite's bioactivity begins with its conversion to NO, supported by numerous studies showing that the cytoprotective effects of nitrite are inhibited by carboxy-PTIO-(2-(4-carboxyphenyl)-4,5-dihydro4,4,5,5,-tetramethyl-1 H-imidazolyl-1-oxy-3-oxide (14). The reduction of nitrite to NO occurs by a number of biochemical pathways including reaction with deoxyhemoglobin (23), myoglobin (24), nonenzymatic disproportionation (25), and reactions catalyzed by both xanthine oxidase (26) and NO synthase (27) under hypoxic conditions.

To assess the potential NO-bioactivity of nitrite, cGMP concentrations were measured in the blood and CSF of the current study as a surrogate marker for the presence of increased systemic and brain NO concentrations, respectively. cGMP concentrations became elevated in blood during iNO treatment, but did not change significantly in the CSF, suggesting the increase in CSF nitrite did not result in increased cerebral NO. In contrast, i.v. infusion of nitrite to blood concentrations approximately 15 -fold higher than baseline levels resulted in a significant increase in both blood and CSF cGMP concentrations. These latter data are consistent with the concept that nitrite serves as a source of NO in the body, with subsequent activation of guanylate cyclase. However, it cannot presently be determined whether the increase in CSF cGMP we observed was a result of nitrite reduction to NO within the brain itself, reduction of nitrite to NO in the blood vessels followed by diffusion of NO into the brain, or by diffusion of cGMP itself from the blood into the CSF.
Other possible carriers of NO bioactivity. Nitrite is not the only potential carrier of NO bioactivity from the lungs to peripheral organs. Other possibilities include s-nitrosated proteins (RSNOs) (28,29), and iron-nitrosyl Hb, HbNO (5). Although $\mathrm{HbNO}$ has traditionally been considered biologically inert due to its stable nature, recent evidence now suggests that $\mathrm{HbNO}$ may release $\mathrm{NO}$ in the arterial vasculature $(5,30)$. RSNOs are formed by NO binding reversibly to the cysteine residues of circulating proteins such as albumin and $\mathrm{Hb}$, resulting in a circulating pool of RSNO capable of releasing NO in the resistance vessels and capillaries $(28,29)$. These carriers, as well as nitrite, may play a part and the findings in the present study do not exclude them. It is also worth noting that the dose of iNO administered in clinical practice (5-20 ppm) is significantly lower than that used in the present study (80 ppm). Dose-ranging studies in both the human $(23,31)$ and mouse (32) demonstrate the vasoactive and cytoprotective effects of nitrite are potent, with physiologic effects observed with increases of blood nitrite concentrations as small as $20 \%$, which approaches the precision limits of the nitrite assay. Our decision to use $80 \mathrm{ppm}$ was based on the desire to ensure measurable increases in blood nitrite concentrations in a minimal number of lambs. Given our observation of increased CSF nitrite concentrations after a 30-min treatment with 80 ppm iNO, it is not unreasonable to assume effective changes in nitrite concentrations are observed in the blood and CSF of patients who are typically treated at lower doses but for periods of hours to days. In addition, the lack of increase in CSF cGMP concentrations at 80 ppm suggests clinical doses of iNO are not likely to activate brain cGMP.

Metabolism of nitrite in brain tissue homogenates. Based on reports that intravascular nitrite is an important regulator of vascular tone after conversion to NO by reaction with deoxyhemoglobin, it is possible that the neuroprotective effects of nitrite are mediated by direct vasoregulation. However, circulating nitrite may also alter organ function via production of s-nitrosated, heme-nitrosylated, or n-nitrosaminated proteins (33). In the present study, we observed no metabolism of nitrite added to brain tissue homogenates in vitro, nor any evidence of NO-modified protein production. These findings are consistent with those of Bryan et al. (33) who observed increased nitrosated protein concentrations in a number of organs, but not in the brain, after intraperitoneal administration of nitrite to mice. Although further studies are needed to evaluate the effects of nitrite on living brain tissue, the current study offers no evidence of direct metabolism of nitrite within the brain.

Effect of iNO on blood oxygen content. As demonstrated in Figure 1, we observed a significant increase in blood oxygen content of iNO-treated lambs, a result of increased blood $\mathrm{Hb}$ concentrations. Given the potent effects of iNO on stimulating renal blood flow and glomerular filtration rates, this may have been caused by decreased plasma volume due to increased glomerular filtration (4), or due to release of erythrocytes into the circulation. In any case, if one assumes no decrease in cardiac output during iNO administration (4), the increase in oxygen-carrying capacity observed in the present studies would equate to a $\sim 20 \%$ increase in systemic oxygen delivery 
and bears further examination as a possible extrapulmonary benefit of iNO in its own right.

Conclusions and perspectives. The finding that iNO results in extrapulmonary NO-mediated effects has heightened interest in the endocrine role of $\mathrm{NO}$ and its byproduct nitrogenoxide species. Growing evidence now suggests nitrite plays a protective role under conditions of hypoxic stress. The results of the present study confirm that iNO treatment results in increased nitrite concentrations in both the blood and CSF. We were unable to observe any reactivity of nitrite within the brain tissue, suggesting any effects of nitrite are mediated by regulation of blood flow from within the vascular lumen as opposed to reactions within the brain tissue. Given the high prevalence of neurologic sequelae in preterm infants and the recent evidence that they may be prevented by iNO treatment, further study of the metabolism of nitrite and other putative mediators of the extrapulmonary effects of iNO carries great therapeutic potential.

Acknowledgments. We thank Shannon Bragg, Jennifer File, and Janet R. Ninnis for their help with these experiments and manuscript preparation.

\section{REFERENCES}

1. Roberts JD Jr, Fineman JR, Morin FC III, Shaul PW, Rimar S, Schreiber MD, Polin RA, Zwass MS, Zayek MM, Gross I, Heymann MA, Zapol WM 1997 Inhaled nitric oxide and persistent pulmonary hypertension of the newborn. The Inhaled Nitric Oxide Study Group. N Engl J Med 336:605-610

2. Clark RH, Kueser TJ, Walker MW, Southgate WM, Huckaby JL, Perez JA, Roy BJ, Keszler M, Kinsella JP 2000 Low-dose nitric oxide therapy for persistent pulmonary hypertension of the newborn. Clinical Inhaled Nitric Oxide Research Group. N Engl J Med 342:469-474

3. The Neonatal Inhaled Nitric Oxide Study Group (NINOS) 1997 Inhaled nitric oxide and hypoxic respiratory failure in infants with congenital diaphragmatic hernia. The Neonatal Inhaled Nitric Oxide Study Group (NINOS). Pediatrics 99:838-845

4. Troncy E, Francoeur M, Salazkin I, Yang F, Charbonneau M, Leclerc G, Vinay P, Blaise G 1997 Extra-pulmonary effects of inhaled nitric oxide in swine with and without phenylephrine. Br J Anaesth 79:631-640

5. Cannon RO III, Schechter AN, Panza JA, Ognibene FP, Pease-Fye ME, Waclawiw MA, Shelhamer JH, Gladwin MT 2001 Effects of inhaled nitric oxide on regional blood flow are consistent with intravascular nitric oxide delivery. J Clin Invest 108:279-287

6. Kermarrec N, Zunic P, Beloucif S, Benessiano J, Drouet L, Payen D 1998 Impact of inhaled nitric oxide on platelet aggregation and fibrinolysis in rats with endotoxic lung injury. Role of cyclic guanosine 5'-monophosphate. Am J Respir Crit Care Med 158:833-839

7. Schreiber MD, Gin-Mestan K, Marks JD, Huo D, Lee G, Srisuparp P 2003 Inhaled nitric oxide in premature infants with the respiratory distress syndrome. N Engl J Med 349:2099-2107

8. Kinsella JP, Cutter GR, Walsh WF, Gerstmann DR, Bose CL, Hart C, Sekar KC, Auten RL, Bhutani VK, Gerdes JS, George TN, Southgate WM, Carriedo H, Couser RJ, Mammel MC, Hall DC, Pappagallo M, Sardesai S, Strain JD, Baier M, Abman SH 2006 Early inhaled nitric oxide therapy in premature newborns with respiratory failure. N Engl J Med 355:354-364

9. Tanaka Y, Hayashi T, Kitajima H, Sumi K, Fujimura M 2007 Inhaled nitric oxide therapy decreases the risk of cerebral palsy in preterm infants with persistent pulmonary hypertension of the newborn. Pediatrics 119:1159-1164

10. Mestan KK, Marks JD, Hecox K, Huo D, Schreiber MD 2005 Neurodevelopmental outcomes of premature infants treated with inhaled nitric oxide. N Engl J Med 353:23-32

11. Kim-Shapiro DB, Schechter AN, Gladwin MT 2006 Unraveling the reactions of nitric oxide, nitrite, and hemoglobin in physiology and therapeutics. Arterioscler Thromb Vasc Biol 26:697-705
12. Shiva S, Wang X, Ringwood LA, Xu X, Yuditskaya S, Annavajjhala V, Miyajima H, Hogg N, Harris ZL, Gladwin MT 2006 Ceruloplasmin is a NO oxidase and nitrite synthase that determines endocrine NO homeostasis. Nat Chem Biol 2:486-493

13. Dejam A, Hunter CJ, Pelletier MM, Hsu LL, Machado RF, Shiva S, Power GG, Kelm M, Gladwin MT, Schechter AN 2005 Erythrocytes are the major intravascular storage sites of nitrite in human blood. Blood 106:734-739

14. Lundberg JO, Weitzberg E, Gladwin MT 2008 The nitrate-nitrite-nitric oxide pathway in physiology and therapeutics. Nat Rev Drug Discov 7:156-167

15. Pelletier MM, Kleinbongard P, Ringwood L, Hito R, Hunter CJ, Schechter AN, Gladwin MT, Dejam A 2006 The measurement of blood and plasma nitrite by chemiluminescence: pitfalls and solutions. Free Radic Biol Med 41:541-548

16. Feelisch M, Rassaf T, Mnaimneh S, Singh N, Bryan NS, Jourd'Heuil D, Kelm M 2002 Concomitant S-, N-, and heme-nitros(yl)ation in biological tissues and fluids: implications for the fate of NO in vivo. FASEB J 16:1775-1785

17. Blood AB, Power GG 2007 In vitro and in vivo kinetic handling of nitrite in blood: effects of varying hemoglobin oxygen saturation. Am J Physiol Heart Circ Physiol 293:H1508-H1517

18. Fox-Robichaud A, Payne D, Hasan SU, Ostrovsky L, Fairhead T, Reinhardt P, Kubes P 1998 Inhaled NO as a viable antiadhesive therapy for ischemia/reperfusion injury of distal microvascular beds. J Clin Invest 101:2497-2505

19. Takahashi Y, Kobayashi H, Tanaka N, Sato T, Takizawa N, Tomita T 1998 Nitrosyl hemoglobin in blood of normoxic and hypoxic sheep during nitric oxide inhalation. Am J Physiol 274:H349-H357

20. Van Meurs KP, Wright LL, Ehrenkranz RA, Lemons JA, Ball MB, Poole WK, Perritt R, Higgins RD, Oh W, Hudak ML, Laptook AR, Shankaran S, Finer NN, Carlo WA, Kennedy KA, Fridriksson JH, Steinhorn RH, Sokol GM, Konduri GG, Aschner JL, Stoll BJ, D'Angio CT, Stevenson DK 2005 Inhaled nitric oxide for premature infants with severe respiratory failure. N Engl J Med 353:13-22

21. Hintz SR, Van Meurs KP, Perritt R, Poole WK, Das A, Stevenson DK, Ehrenkranz RA, Lemons JA, Vohr BR, Heyne R, Childers DO, Peralta-Carcelen M, Dusick A, Johnson YR, Morris B, Dillard R, Vaucher Y, Steichen J, Adams-Chapman I, Konduri G, Myers GJ, de Ungria M, Tyson JE, Higgins RD 2007 Neurodevelopmental outcomes of premature infants with severe respiratory failure enrolled in a randomized controlled trial of inhaled nitric oxide. J Pediatr 151:16-22

22. Kim-Shapiro DB, Gladwin MT, Patel RP, Hogg N 2005 The reaction between nitrite and hemoglobin: the role of nitrite in hemoglobin-mediated hypoxic vasodilation. J Inorg Biochem 99:237-246

23. Cosby K, Partovi KS, Crawford JH, Patel RP, Reiter CD, Martyr S, Yang BK, Waclawiw MA, Zalos G, Xu X, Huang KT, Shields H, Kim-Shapiro DB, Schechter AN, Cannon RO III, Gladwin MT 2003 Nitrite reduction to nitric oxide by deoxyhemoglobin vasodilates the human circulation. Nat Med 9:1498-1505

24. Huang Z, Shiva S, Kim-Shapiro DB, Patel RP, Ringwood LA, Irby CE, Huang KT, Ho C, Hogg N, Schechter AN, Gladwin MT 2005 Enzymatic function of hemoglobin as a nitrite reductase that produces NO under allosteric control. J Clin Invest 115:2099-2107

25. Zweier JL, Samouilov A, Kuppusamy P 1999 Non-enzymatic nitric oxide synthesis in biological systems. Biochim Biophys Acta 1411:250-262

26. Zhang Z, Naughton D, Winyard PG, Benjamin N, Blake DR, Symons MC 1998 Generation of nitric oxide by a nitrite reductase activity of xanthine oxidase: a potential pathway for nitric oxide formation in the absence of nitric oxide synthase activity. Biochem Biophys Res Commun 249:767-772

27. Vanin AF, Bevers LM, Slama-Schwok A, van Faassen EE 2007 Nitric oxide synthase reduces nitrite to NO under anoxia. Cell Mol Life Sci 64:96-103

28. McMahon TJ, Doctor A 2006 Extrapulmonary effects of inhaled nitric oxide: role of reversible S-nitrosylation of erythrocytic hemoglobin. Proc Am Thorac Soc 3:153160

29. Ng ES, Jourd'heuil D, McCord JM, Hernandez D, Yasui M, Knight D, Kubes P 2004 Enhanced S-nitroso-albumin formation from inhaled NO during ischemia/ reperfusion. Circ Res 94:559-565

30. Grubina R, Huang Z, Shiva S, Joshi MS, Azarov I, Basu S, Ringwood LA, Jiang A, Hogg N, Kim-Shapiro DB, Gladwin MT 2007 Concerted nitric oxide formation and release from the simultaneous reactions of nitrite with deoxy- and oxyhemoglobin. J Biol Chem 282:12916-12927

31. Dejam A, Hunter CJ, Tremonti C, Pluta RM, Hon YY, Grimes G, Partovi K, Pelletier MM, Oldfield EH, Cannon RO III, Schechter AN, Gladwin MT 2007 Nitrite infusion in humans and nonhuman primates: endocrine effects, pharmacokinetics, and tolerance formation. Circulation 116:1821-1831

32. Duranski MR, Greer JJ, Dejam A, Jaganmohan S, Hogg N, Langston W, Patel RP, Yet SF, Wang X, Kevil CG, Gladwin MT, Lefer DJ 2005 Cytoprotective effects of nitrite during in vivo ischemia-reperfusion of the heart and liver. J Clin Invest 115:1232-1240

33. Bryan NS, Fernandez BO, Bauer SM, Garcia-Saura MF, Milsom AB, Rassaf T, Maloney RE, Bharti A, Rodriguez J, Feelisch M 2005 Nitrite is a signaling molecule and regulator of gene expression in mammalian tissues. Nat Chem Biol 1:290-297 